\title{
An Empirical Study on the Effects of Industrial Structure on Economic Fluctuation in China
}

\author{
Fang-Fang Zhang* \\ Northwest Normal University \\ Lanzhou, China
}

\begin{abstract}
This paper built an econometric model to explore the research topic from optimization of industrial structure, based on the concrete analysis of the development course of industrial structure and the characteristics of economic fluctuation. The results show that Chinese overall industrial structure layout is becoming more and more rational and the stability of various provinces' economic growth is gradually increasing, although the changes of research objects in various regions have obvious stage characteristics. Using the PAVR model, it shows that the impact of changes in industrial structure has a lasting effect on economic fluctuations. The optimization of industrial structure is an important factor influencing economic fluctuations, its ironing effect on the economy varies from region to region, and is mainly reflected in the eastern developed provinces. The innovation of the paper lies in the use of panel data and describing the relationship between the two from the static and dynamic aspects.
\end{abstract}

Keywords-economic fluctuation; industrial structure change; optimization of industrial structure; high-quality development

\section{INTRODUCTION}

In recent years, the global economic situation is undergoing profound and complex changes, the world economy is confronting more risks and uncertainties; thus China's economic growth showed a more obvious tendency to volatility convergence. In 2010, the economic growth rate was $10.6 \%$ year-on-year. In 2012, it was significantly lower than 8\%; since then, the actual growth rate of China's economy has remained within the $7 \%$ range; in 2019, China's overall economic downward pressure is still relatively large, and some provinces have not yet reached their growth targets.

Economic growth shifts, structural adjustment pains, and early policies to be digested, Chinese government timely put forward the "supply-side structural reform" , the Fourth Plenary Session of the 19th Central Committee of the Communist Party of China stressed the need to deliver highquality economic development.

Embroidering on the domestic supply-side structural reforms, the government's inclusiveness for economic growth has continued to increase , the government has always adhered to the new development concept and adopted a series of proactive fiscal policies and prudent monetary policies, however relying solely on these policies cannot effectively relieve the current economic pressure, macroeconomic operations are compatible with economic cyclical fluctuations and structural changes, including industries, factor inputs, and growth momentum, structural issues that are independent and interconnected, need to be addressed through reforms; in hence, economic volatility cannot be said in one word. In the context of China's gradual search for new economic kinetic energy and the adjustment of industrial structure has not yet reached a reasonable level, it is of practical significance to analyze economic fluctuations from an industrial perspective and rationally view economic cycle fluctuations, which is conducive to reducing risks of economic fluctuations, stabilizing economic growth, and easing the downward pressure on the Chinese economy.

The article discusses the development process of China's industrial structure since the reform and opening up, intends to analyze the actual impact of industrial structure on economic fluctuations through empirical analysis, sums up experience to put forward suggestions that are conducive to stable and healthy development of the economy.

\section{LITERATURE REVIEW}

Business cycle theory has deep origins and rich research results. From Marx and Engels to classical economics, neoclassical economics and so on, many scholars have constructed a complete business cycle theory system according to the research results of the business cycle, which provides a profound theoretical basis for modern researches. The development economists realized the connection between the change of industrial structure and economic fluctuations earlier (Baumol, 1967), explaining the formation of economic fluctuations from the flow of technology and labor and the allocation of resources; Kuznets (1971) argues that the industrial structure change was the root cause of economic cycle fluctuation [1], Cherry(1989) believes that the driving effect of economic growth would lead to industrial structure change, and the resulting factor transfer within departments would promote economic growth, such irregular growth and alternate movement would form economic fluctuations [2]; Peneder (2003) constructed an econometric model to study the impact of structural changes on economic fluctuations, and believes that the improvement of industrial productivity and structural changes would have a positive effect on economic fluctuations [3]

Domestic scholars also paid more attention to topics such as industrial structure and economic fluctuations. The research object has shifted from the relationship between industrial 
structure and economic growth (Liu Wei, 2008) to the impact of structural changes on economic fluctuations (Yuan Jiang, 2009); researchers have elaborated the influence path between the two, and pointed out that there was a mutual influence relationship between industrial structure change and economic fluctuations (Ma Jiantang, 1988; Li yun'e, 2008; Wang Yanjun, 2011; Gan Chunhui, 2011; ZhangJifeng, 2019).

With the deepening of the research, relevant research literature is more abundant, but there is no consistent conclusion on the impact of industrial structure on economic fluctuations; some scholars' research results show that the change of industrial structure has a smoothing effect on economic fluctuations. In the high-quality development stage of China's economy, industrial changes are measured from the dimensions of rationalization and upgrading of industrial structure [4] (Yao Tingting et al., 2019; Liu Huajun, 2019), the research results illustrate its smoothing effect on economic fluctuations and also explain China's "great moderation" phenomenon of economic fluctuations in recent years [5] $(\mathrm{Lv}$ Yiqing, 2018).

Other scholars argue that there is an aggravating effect. Jiang Yongling (2015) believes that the sustainability of industrial fluctuations would increase the impact on economic fluctuations [6]. Zhao Xujie et al. (2018) constructed a general equilibrium model, and consider that from the perspective of transmission paths such as labor price, the inter-industry transfer is likely to aggravate the fluctuation of economic cycle [7]; Li Xiaojuan (2017) also holds that the change of industrial structure is an important cause of the fluctuation of China's economy, and his research proves that there are "structural acceleration" and "structural deceleration" periods in the process of China's economic development[8]. Gan Chunhui's (2011) point out that the industrial structure upgrading and rationalization have different impact on the economic fluctuations, the rationalization of industrial structure may smooth the economic fluctuation, while the upgrading of industrial structure would bring about economic fluctuations [9].

Early scholars' research design mostly took China's macro data as samples (Fu Linghui, 2010; Li Qiang, 2012), occasionally some scholars analyzed the impact of industrial structure changes on economic fluctuations from the regional or urban level (Pang Zhen, 2013; Zhang Jifeng, 2019), the existing research results have important reference value for the research design of this article, but there is few research on the region or city, which provides an opportunity for this research. Considering the heterogeneity of internal changes in the industrial structure of each province in the time and space dimensions, the difference in factor endowment and selection, this paper will use provincial panel data for empirical analysis to achieve research purposes.

\section{DEVELOPMENT PROCESS AND DYNAMIC RELATIONSHIP BETWEEN CHANGES IN INDUSTRIAL STRUCTURE AND ECONOMIC FLUCTUATIONS}

\section{A. Trends of China's Three Industries}

This part focuses on describing the changing trends of China's three industrial structures from 1978 to 2018 in terms of changes in the proportion of output value and the composition of employees, and analyzing the economic fluctuation characteristics of provinces and cities with the help of HP filtering method.

The share of industries' output value over the years is an intuitive reflection of changes in the domestic output structure. As shown in the Fig 1, in China the primary industry declined as a whole, the secondary industry fluctuated and descended, and the tertiary industry showed a momentum of rapid rise and gradually replaced the tertiary industry as the leading industry.

In 2015 , the tertiary industry accounts for more than $50 \%$ of the national economy and $40 \%$ of its employees; In the transformation of China's industrial structure from industrialization to regarding service industry as a new engine for growth, the trend of "economic service" has gradually emerged and become increasingly prominent; In the future, in the process of promoting the upgrading of the internal structure of the service industry with human capital, high-end manufacturing and knowledge consumption etc, servicization will become an inevitable trend for China's economic development.

Describe the China's industrial structure changes further. In the early stage of reform and opening up, China was in the initial stage of rural reform with low labor productivity; the implementation of rural household contract responsibility system, government purchases and sales, and other policies greatly improved agricultural labor productivity, drove production enthusiasm, and promoted rural economic development; The proportion of primary industry increased from $27.7 \%$ in 1978 to $31.5 \%$ in 1984 , while the proportion of the secondary industry declined. Taking 1985 as the node, the proportion of China's tertiary industry output value exceeded the proportion of primary industry for the first time, and the industrial structure changed from "two one three" to "two three one" pattern, this situation continued until 2011. At the same time, the tertiary industry has developed rapidly, in 2012 , its proportion exceeded the proportion of the output value of the secondary industry; while the proportion of the output value of the primary industry continued to decline, and the industrial form changed into "three two one" pattern(as shown in Fig 1).

From the perspective of economic fluctuations, the economic growth was extremely unstable from 1978 to 1991 , and the fluctuations were more severe; from 1992 to 2007, it showed an approximately "U" shaped growth, since then the amplitude of economic fluctuations has shrunk. Combined with the changes in the proportion of the three industries, China's economic fluctuations have been affected by changes of the industrial structure, which are currently mainly affected by changes of the secondary and tertiary industries, in recent years the stability of economic growth has increased significantly. 
From the perspective of the composition of employees in various industries, since the reform and opening up, the proportion of employees in the primary industry in China has plummeted, and more labor force has shifted to secondary and tertiary industries with higher incomes and wider employment. Since 1994, the number of employees in the tertiary industry has surpassed that in the second industry, in 2011, the proportion of employees in the three industries has changed from the original "one two three" to the "three two one" structure; the continuous advancement has prompted more labor to transfer from agriculture to other industries. It has been transformed into the "three two one" structure since 2014 and has continued to this day (as shown in Fig 2).

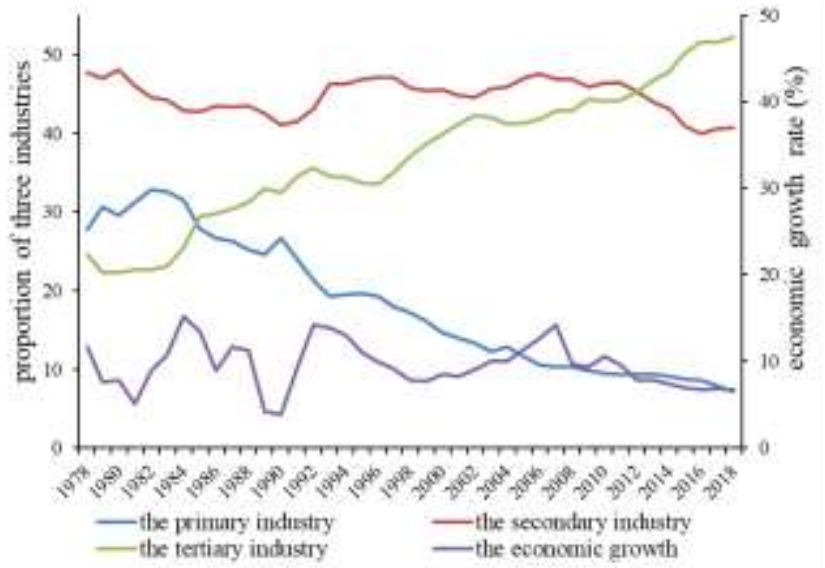

Fig. 1. China's economic fluctuations and the change trends of three industries' proportion from 1978 to 2018

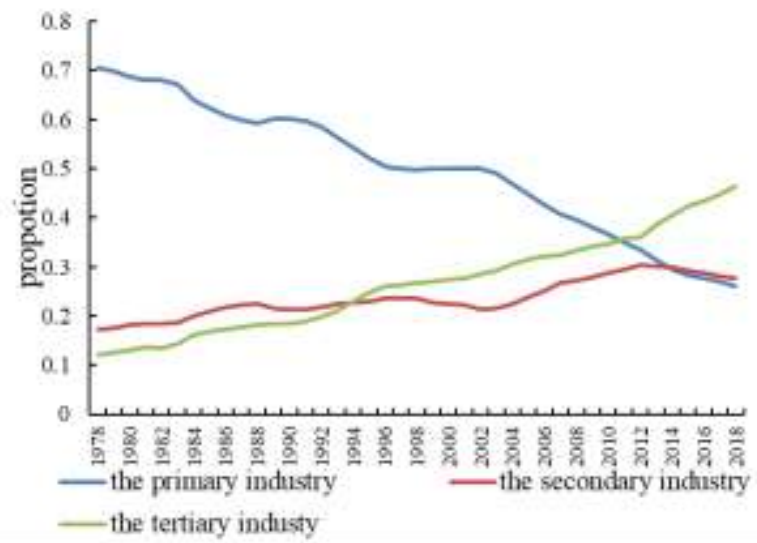

Fig. 2. Changes in the employment structure of China's three industries from 1978 to 2018

\section{B. Regional Differences in Industrial Structure Changes}

The data of the three industries' output value from 2000 to 2018 in various provinces show that, the changes in the industrial structure reflect obvious regional differences. Since 2002 , the proportion of the primary industry in the eastern region has been less than $10 \%$, and has been in a declining trend ever since; the secondary industry itself has a good industrial base, and its proportion has started to decline after a small increase; the share of the tertiary industry has showed increase tendency in fluctuation, which has exceeded $50 \%$ in 2014; the structural transformation of the eastern region have benefited from own good industrial foundation ,superior geographical location, which has also resorted to the active and initiative development under the innovation strategy and opening to the outside world in recent years. The change trend in the central region is very different, whose secondary industry still has a high proportion; so that the share of the secondary and tertiary industries is equivalent; Although the proportion of the tertiary industry in the western region fluctuates greatly, its ratio has increased significantly, and has transformed into "three two one" industrial development pattern.

The flow of labor elements lies in the full realization of employment. Compared with the central and western regions, the eastern region has a stronger ability to absorb labor factors, can provide employees with more opportunities, higher income and deeper development, forming a certain labor advantages and attracting more labor inflow.

\section{Characteristics of Economic Fluctuations in Our Provinces}

In this part, HP (Hodrick-Prescott) filtering method is used to remove the trend component of the research object, and the remaining volatility term is used to measure the economic fluctuation.

Using 2000 as the base period, the actual GDP value was obtained by the conversion of the historical price index of each province, the possible heteroscedasticity of the data can be eliminated by logarithm, and then the components of the economic cycle fluctuations of each province were obtained by the analysis of HP filter. As for the value of smoothing parameter, Zhu Baohua (2009) and Cao Linfeng (2014) et al. considered that the research results obtained by $=100$ were more in line with the actual situation in China. Based on the above explanation, the economic volatility chart of each province in China from 1999 to 2018 is obtained (as Fig 3 shown). According to the "valley - valley" division method, there are obvious peaks and valleys in the economic fluctuations of the provinces, although the time of crests and troughs are different, except for some provinces such as Inner Mongolia and Liaoning, the trend of economic fluctuations of our provinces is relatively consistent. The impact of the Asian financial crisis, coupled with the problems of insufficient effective demand and deflation in the domestic economic operation, China's economy experienced a trough around 2000. After China's successful accession into the WTO, it gradually integrated into the wave of globalization; driven by three driving carriages--export, consumption and investment, China ushered in a period of rapid economic growth. However, the global financial crisis, which evolved from the subprime mortgage crisis in the United States, quickly pulled China's economy from its peak to the trough, and the economy has obviously dropped. In 2010, China's new round of economic cycle has started, under the background of "three-phase superposition", China's economy experienced a short period of acceleration, followed by a downward trend. The judgment of "new normal" is put forward, China's economy is transitioning 
from a phase of rapid growth to a stage of high-quality development, the economic growth rate continues the previous downward trend; however, since 2015 , the economic volatility of most provinces has been significantly reduced, and the stability of economic growth has been gradually enhanced.

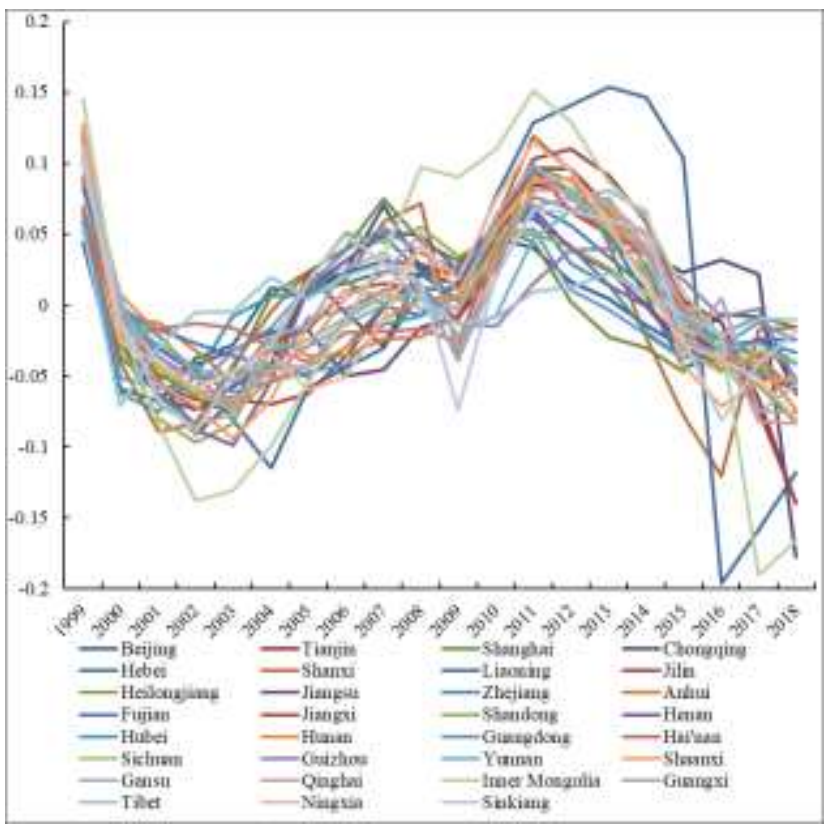

Fig. 3. HP Filter Analysis Results of Economic Growth Status of our Provinces in China

\section{Dynamic Relationship between Industrial Structure Change and Economic Fluctuation}

To further describe the impact of industrial structure changes on economic fluctuations, the panel vector autoregression model is used to analyze the dynamic relationship between variables. Choose Levin Lin Chu, Fisher-type and Harris-Tzavalis methods to test the variables' stationarity: the filter value of GDP- lngdp_hp, the proportion of the primary industry- $p i$, the proportion of the secondary industry -si and the proportion of the tertiary industry- $t i$.

The results show that: the dependent variables $s i$ and $t i$ have not passed the stationarity test, so use the variables' difference form for subsequent analysis. In view of the selection of model lag terms, according to the minimum information criteria MAIC and MBIC, it is found that the model constructed with first-order lag conforms to these standards, whose all the characteristic roots are located in the unit circle and satisfy the stability conditions; therefore, the first-order lag PVAR model is used for follow-up analysis. The Granger causality test of variables indicates that there is a two-way Granger causality among variables, that is, the change of industrial structure and economic fluctuations affect mutually. The subsequent impulse-response analysis is carried out to test the response of economic fluctuation when given the positive impact of the industrial structure. The test results are shown as follows (the left side of the diagram is the response of economic fluctuations to the impact of industrial structure change, and the right side is the response of structural changes to the impact of economic fluctuations).

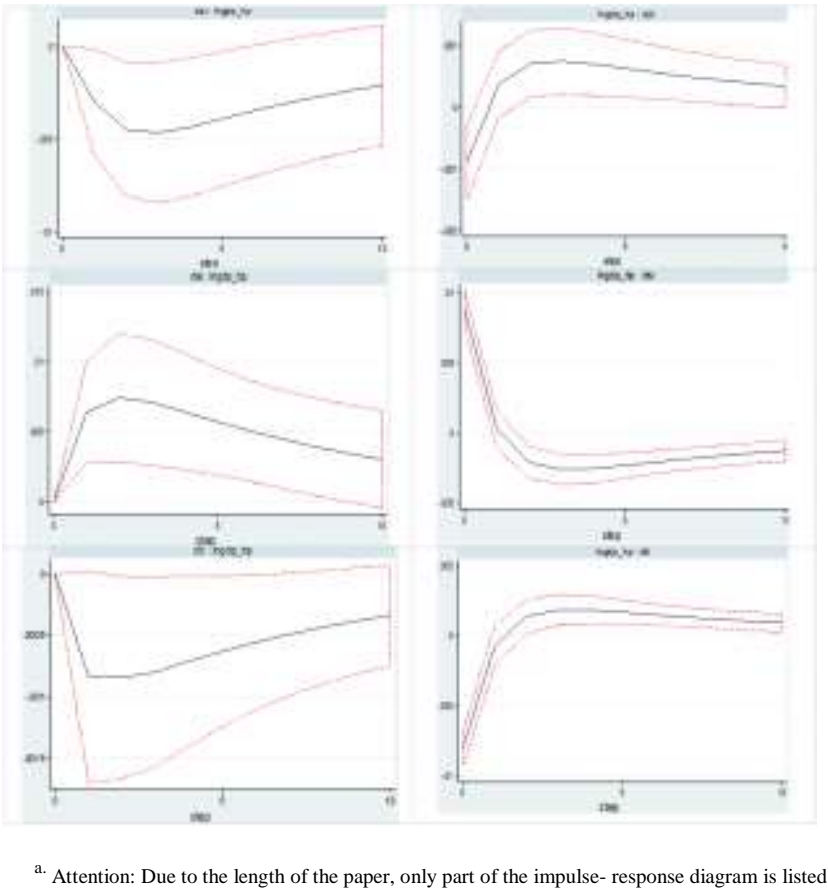

Fig. 4. The impulse-response diagram

As shown in Fig 4, given the impulse variable, the response variable has the following response: given the impulse variable's one-unit standard error rate shock, the response variable immediately makes a sensitive response and reaches the maximum value of the response in the third phase; within forecast period, the impact of the impulse variable shock gradually increases, then slowly weakens, and lasts longer. Specifically, the impact of the changes in the primary and tertiary industries has a negative effect on economic fluctuations, after reaching the maximum value of the impact, it begins to converge to 0 in the fifth phase, while the effect of the changes in the secondary industry is opposite. By comparison, it can find that the impact of the change in the secondary industry on the economic fluctuation is larger than that of other industries. Similarly, economic fluctuations will also affect the structural changes, the impact of economic fluctuations on the structural changes of the primary and tertiary industries has a changing process from negative to positive, from strong to weak, and gradually converge to 0 ; the response of the secondary industry to it is opposite. The impulse- response results show that, changes in the industrial structures will bring about a relatively lasting effect on economic fluctuations, which is greater than the impact of economic fluctuations on the industrial structures.

\section{EMPIRICAL ANALYSIS}

\section{A. Variable Selection and Data Sources}

1) Variable selection. In this part, through selecting economic fluctuation indicators and industrial structure change indicators, the panel data model is constructed to specifically analyze the impact of industrial structure changes on economic fluctuations. The established model is as follows:

$$
V_{i t}=\beta_{0}+\beta_{k} s t r u_{i t}+\theta_{i} x_{i t}+\mu_{i}+\varepsilon_{i t}
$$


Where, $i$ refers to province, $t$ is the time variable, $V_{i t}$ refers to the economic fluctuation index, $s t r u_{i t}$ represents the change index of industrial structure of each province or city, and $x_{i t}$ represents other control variables. In terms of the selection of economic fluctuation indicators, with reference to the practices of Lu Er'po, Zeng Wuyi (2008) and Gan Chunhui (2011) and the idea of coefficient of variation, use the standard error of the average GDP growth rate as the measurement index of economic fluctuation. The calculation is as follows:

$$
V_{j}=\sigma_{i z-T+1} / \frac{1}{T} \sum_{m=i-T+1}^{f} g_{i m}
$$

$g_{m}$ denotes the actual GDP growth rate, $\sigma_{i t-T+1}$ is the standard deviation of the growth rate in the period it $-T+1$ to $t$; $T$ is the time span, whose value is set as 5 based on the period division of China's economic fluctuations and the research results of previous scholars.

Core explanatory variables. The signs of the increasing proportion of the service industry in the industrial structure change have attracted more attention from scholars, but it cannot be simplified as the numerical change of the proportion of the output value of three industries, the in-depth study of the change of the industrial structure involves the optimization and upgrading of the structure. Based on the existing research, most scholars analyze the upgrading of industrial structure from the perspective of rationalization and optimization of industrial structure, so this article establishes an advanced industrial structure indicator, which is calculated as follows:

$$
S U=(P+N) / 2, P=\sum_{i=1}^{3} p_{i} \cdot i, N=\sum_{i=1}^{3} n_{i}+i
$$

$P_{i}$ represents the proportion of the output value of the $i$ industry, $n_{i}$ means the proportion of the number of employment of $i$ industry in the total number of employees at the end of the year. The value of $S U$ is between $(1,3)$, and the closer it is to 3 , the more obvious the tendency of regional industrial structure toward servicization is, on the contrary, the industrial structure is less advanced.

Selection of other control variables. Consider the internal and external factors influencing the economic fluctuation:(1) investment factor $(f d i)$ : as one of the troika for economic growth, investment is also an effective factor to stimulate economic growth, and opening to the outside world further promotes the development of foreign direct investment; This article selects the actual utilization of foreign capital - the growth rate of foreign direct investment as the variable affecting the fluctuation of economic growth. (2) policy factor (gov): Zhou Ye'an's (2008) study explained the inducing effect of fiscal expenditure on economic fluctuations [10], so this paper selects the year-on-year growth rate of local fiscal budget expenditure for analysis. (3) technology factor $(R D)$ : Feng Yunting (2020) believes that technological innovation has a balanced effect on the fluctuation of economic growth[11], and old growth drivers are yet to be replaced by new ones, which should committed to technological innovation. The article selects the change of internal expenditure of R\&D expenditure as the measurement index. (4) trade factor (ex) : use changes in export volume to analyze the influence of on economic fluctuations.

2) data sources. This paper research objects involve 30 provinces and cities (autonomous regions) in China. considering the data's size and availability, Tibet is not included in the research scope. Most of the data used in this paper are from the local statistical yearbook and Chinese city statistical yearbook, the missing data are supplemented by the China economic database and the Wind database, the missing data of internal expenditure index of $\mathrm{R} \& \mathrm{D}$ expenditure are obtained from the statistical bulletin of national science and technology investment issued by the ministry of finance over the years.

\section{B. Results Analysis}

There are usually three setting types of panel data model: fixed effect model, random effect model, and mixed model. Before the analysis, the variables are also tested for stationarity (the test method is no longer exhaustive), the results show that the selected variables are all stationary series, which can avoid the problem of pseudo regression. In model selection, the F test and LR test statistics are established by using the sum of squared residuals with or without constraints to judge whether the mixed model is a fixed-effect model or not; and then use Hausman test to make a choice between fixed-effect and random-effect models. Combined with the results of the previous filter analysis of economic fluctuations in our provinces, it is found that the research object has obvious individual effects. the establishment of the model should take into account that the coefficients of the variables vary from individual to individual. The LSDV test results prove that the individual effects are more significant than the time effect. Finally, the article chooses to establish individual fixed effect variable coefficient models, the following tables show the results of LSDV test and variable intercept regression model under the three model setting modes.

TABLE I. THE EMPIRICAL RESULTS

\begin{tabular}{|c|c|c|c|}
\hline Variables & Pool & Fixed Effect & Random Effect \\
\hline \multirow{2}{*}{ gov } & -0.24087 & -0.2352 & -0.23425 \\
\cline { 2 - 4 } & -0.04417 & -0.0562 & -0.04073 \\
\hline \multirow{2}{*}{ fdi } & -0.00483 & -0.00432 & -0.00444 \\
\cline { 2 - 4 } & -0.069 & -0.00899 & -0.01165 \\
\hline \multirow{2}{*}{ ex } & -0.00975 & -0.00778 & -0.0082 \\
\cline { 2 - 4 } & -0.00919 & -0.00818 & -0.00854 \\
\hline \multirow{2}{*}{ RD } & -0.03408 & -0.02633 & -0.02789 \\
\cline { 2 - 4 } & -0.01514 & -0.01256 & -0.01302 \\
\hline \multirow{2}{*}{ su } & 0.09681 & 0.30644 & 0.26411 \\
\cline { 2 - 4 } & -0.26362 & -0.08813 & -0.14449 \\
\hline \multirow{2}{*}{ C } & 0.1913 & 0.18452 & 0.1859 \\
\cline { 2 - 4 } & -0.0101 & -0.01851 & -0.01187 \\
\hline R square & 0.4772 & 0.476 & 0.463 \\
\hline Prob>F & 0 & 0.0003 & 0 \\
\hline Hausman & - & 0 & 0 \\
\hline
\end{tabular}


TABLE II. ThE RESUlTS OF LSDV TEST

\begin{tabular}{|c|c|c|c|c|c|}
\hline Variables & & \multicolumn{2}{|c|}{ Individual } & \multicolumn{2}{|c|}{ Individual } \\
\hline \multirow{2}{*}{ gov } & -0.173 & \multirow{2}{*}{ ah } & -0.164 & \multirow{2}{*}{ hub } & -0.16696 \\
\hline & -0.0596 & & -0.027 & & -0.0259 \\
\hline \multirow{2}{*}{$\mathrm{RD}$} & -0.134 & \multirow{2}{*}{$\mathrm{bj}$} & -0.1755 & \multirow{2}{*}{ guizh } & -0.17821 \\
\hline & -0.0512 & & -0.028 & & -0.0262 \\
\hline \multirow{2}{*}{ ex } & -0.085 & \multirow{2}{*}{$\mathrm{cq}$} & -0.1487 & \multirow{2}{*}{ jil } & -0.13284 \\
\hline & -0.06 & & -0.026 & & -0.0278 \\
\hline \multirow{2}{*}{ fdi } & 0.05465 & \multirow{2}{*}{$\mathrm{fj}$} & -0.1691 & \multirow{2}{*}{ hunan } & -0.17198 \\
\hline & -0.02 & & -0.026 & & -0.0254 \\
\hline \multirow{2}{*}{ su } & -0.0948 & \multirow{2}{*}{$\mathrm{gd}$} & -0.17389 & \multirow{2}{*}{ jsu } & -0.18291 \\
\hline & -0.021 & & -0.0279 & & -0.0249 \\
\hline samples & 600 & \multirow{2}{*}{ gsu } & -0.1628 & \multirow{2}{*}{ jxi } & -0.16825 \\
\hline Prob $>F$ & 0 & & -0.02867 & & -0.0297 \\
\hline \multirow[t]{2}{*}{$\mathrm{R}^{2}$} & 0.524 & \multirow{2}{*}{ gxi } & -0.1568 & \multirow{2}{*}{ lning } & -0.01714 \\
\hline & $\longrightarrow$ & & -0.0249 & & -0.079 \\
\hline
\end{tabular}

Analyze the regression model's results concretely. Except for Beijing, Jiangsu, Shanghai, Tianjin, Zhejiang, Guangdong and so on, the core explanatory variable - optimization of industrial structure is an important factor influencing economic fluctuations, while in the above-mentioned economically developed regions, it has a certain suppressing effect on economic fluctuations. The new normal state means that the industrialization experience of developed countries cannot be copied and applied to the treatment of the transitioning problems that China faces in the industrialization process, which are different from those of developed countries; the new normal reflects new growth rates, development methods, and sources of power, corresponding to the requirements of highquality economic development; the future direction of China's economic development is to drive changes in the supply-side industrial structure from changes in the demand-side demand structure, enhance the driving force for technological innovation, and gradually advancing from industrialization to economic service, and integrating "economic service" into cultivation

In the process of the service industry being a new engine for future economic growth, combined with human capital, knowledge production, factor reconfiguration, etc., under the basic guidance of system reform and innovation, it promotes the joint development of industry and service industry; Transfers between industries have narrowed the gap in productivity levels through technological advancement, driven the flow of production factors from low-productivity sectors to high-productivity sectors, and improved the labor productivity of the entire society, thereby promoting changes in the industrial structure. Based on the above description, the role of the industrial structure advanced in smoothing economic fluctuations occurs in more economically developed regions, where tertiary industry accounts for a relatively high proportion and the labor productivity sector is relatively small. The industry is adjusted through technological upgrading to achieve the ratio between agriculture and industry Appropriate state, adjust the level of social division of labor and improve the efficiency of factor allocation; therefore, from the overall development level of China's industrialization process, the promotion of industrial structure has not fully released the promotion of economic development, and the ironing effect on economic fluctuations needs to be further enhanced.

From the perspective of control variables, the influence coefficient of fiscal expenditure change on economic fluctuation in most provinces is significantly negative, which indicates that this region has effectively played the function of automatic fiscal stabilizer. But in Guizhou, Hainan, An'hui, Hubei, Sichuan and other places, to a certain extent, the changes of fiscal spending have exacerbated regional economic fluctuations, this may be related to the long-term fiscal imbalances in the region, which will exert a restraining effect on economic development and aggravate local economic fluctuations

The impact of changes in export volume on economic fluctuations varies with regions. The traditional foreign trade provinces represented by Guangdong and Zhejiang have large scale of import and export trades and high foreign-trade dependence; However, due to the adverse effect of China-US economic and trade frictions, coupled with the slowdown of the growth of major economics, the growth rate of imports and exports has obviously narrowed, and there are drastic fluctuations in the regional economy. It is necessary to further optimize the export structure, diversify trade destinations, and take advantage of the "Belt and Road" to fully exploit the export advantages of major foreign trade provinces; in the some Midwest provinces-Shanxi, Shaanxi, Chongqing, Jiangxi, Hainan, Yunnan and so on, the change of export has avoid the economic fluctuations, which is not unrelated to the advancement of the "Belt and Road" initiative, it has brought huge development opportunities to the central provinces, promoted a steady increase in regional export growth, and formed important node cities like Shaanxi. However, economic fluctuations in Guizhou, Qinghai, Ningxia are still susceptible to export trades, it is possible that these regions' foreign trade started late, and the scale of foreign trade is relatively small, which are easily affected by the external trade environment and changes in the import and export volume of internal foreign trade companies.

The external shocks brought about by changes in foreign direct investment do not reflect the effect of significantly smoothing economic fluctuations, which may be related to the local investment environment, market access and other conditions, investment access means market permission; The investment environment is bound up with the production costs of the stationed area, and is susceptible to government policies and the competitiveness of local products, the profit-driven nature of capital expulsions investors to seek cost depressions and profit highlands. Judging from the current phenomenon of some local enterprises return and industrial transfer in Southeast Asian countries, on the one hand, it is necessary to build a more investment-friendly environment and minimize the impact of the investment with a complete industrial supporting system, high infrastructure level, and continuously improving the quality of labor; on the other hand, China needs to further increase the proportion of high-end industrial 
development, reduce external dependence, improve the ability to withstand external shocks, and ease economic fluctuations.

As a representative indicator of science and technology investment, the empirical results show that the change of internal expenditure of R\&D funds has a negative impact on economic fluctuations, which is consistent with the basic facts. Chinese investment of science and technology keeps increasing, correspondingly the proportion of $\mathrm{R} \& \mathrm{D}$ investment keeps increasing, and the investment intensity keeps increasing. This will play an important and beneficial role in strengthening the potential driving force of economic development, innovating the economic development model, and enhancing economic stability. Science and technology expenditure depends on the two-way input of the central and local governments, Beijing, Shanghai, Guangdong and other places have far more investment in research and development funds than other provinces, while some regions have relatively weak investment intensity, investment efficiency, the growth of core scientific and technological achievements is not entirely proportional to that of inputs ,therefore it draws inconsistent conclusions from other regions.; It is necessary to study the layout of inputs elaborately to improve the effectiveness and pertinence of capital occupancy.

\section{Robustness Test}

The article conducts a robust test of the model results by replacing the explained variables, and selects the GDP growth rate per capita as the replacement variable for the actual GDP growth rate to re-model, it shows that the modeling results are not significantly different from the previous ones., the ironing effect of economic fluctuations has not been fully exerted, and the conclusions obtained by the above model are robust.

\section{CONCLUSION}

Based on the aforementioned development process of China's industrial structure changes and economic fluctuations, as well as the characteristics of regional industrial structure changes, using the data of 30 provinces in China from 1999 to 2018, the panel model was established to test its impact on economic fluctuations, the conclusions are as follows:

First, the layout of China's industrial structure is becoming more and more rational, and the tendency of economic servicization is more prominent in the process of high-quality economic development; from a regional perspective, there are obvious regional differences in the characteristics of changes in industrial structure among provinces, and the eastern region takes the lead in developing its belt There are certain advantages; the economic fluctuations of the provinces are slightly different, but they correspond to economic facts. After years of development, the economic stability of most regions has gradually increased.

Second, changes in the industrial structure are an important cause of economic changes, and their impact is more persistent; compared with the intensification effect of economic fluctuations in the central and western regions, the advanced industrial structure in the eastern developed region has a more distinct ironing effect on economic fluctuations; it indirectly indicates that this effect corresponds to a certain level of economic development and structural layout, which differs in different regions.

In conclusion, the smooth operation of China's economy cannot be achieved without the coordination of various factors at home and abroad. All regions should continue to persist in reform and innovation, find more impetus for economic growth, and spread the fruits of innovation. Currently our country has entered the crucial period in which new global growth drivers will take the place of old ones, we must advance structural reforms, overcome the development board by promoting new infrastructure construction and development of digital economy, develop new technologies, industries and forms of business, form an industrial structure that adapts to the future development trends, promote the advancement of industrial structure, and give full play to the role of it in the economy.

The Fourth Plenary Session of the 19th Central Committee of the Communist Party of China made a detailed explanation on the modernization of China's national governance system and governance capacity, similarly, the efficiency and resilience of our economics cannot be achieved without the effective management of the government. Local governments should adapt their measures to local conditions, enhance the competitiveness of enterprises in OFDI through effective guidance, and improve the business environment so as to seek win-win outcomes with closer cooperation; We should give full play to the basic role of public finance in promoting the rational allocation of resources and ensuring the smooth operation of the national economy, develop a future-oriented policy framework and management system development so as to better benefit the peoples.

\section{ACKNOWLEDGMENT}

Fund project: this research was subsidized by the postgraduate research grants project of Northwest Normal University (project number: 2019KYZZ022023).

\section{REFERENCES}

[1] Kuznets S S. Economic growth of nations [J], 1971.

[2] Cherry. A Comparative Study of Industrialization and Economic Growth Shanghai: Sanlian Bookstore Shanghai Branch, 1989.

[3] Peneder M. Industrial structure and aggregate growth [J]. Structural change and economic dynamics, 2003, 14 (4): 427-448

[4] Yao Tingting, Huang Yunlin, Guo Yahui. The Impact of Industrial Structure Changes on Economic Fluctuations under the Background of "Industrial Structure Softening" _ An Empirical Study Based on Provincial Capital City Panel Data [J]. Exploration of Economic Problems, 2019 (06): 143-155.

[5] Lv Yiqing, Deng Xiang. How does the upgrading of the industrial structure "smooth" China's macroeconomic fluctuations-An analysis of the DSGE model based on the endogenous industrial structure [J]. Finance and Trade Research, 2018, 29 (02): 1-10

[6] Jiang Yongling, Zhang Jingyi, Shi Zhanzhong. Distribution of China's industrial structure and economic fluctuations $[\mathrm{J}]$. Economics and Management Research, 2015, 36 (01): 3-10

[7] Zhao Xujie, Guo Qingwang. Changes in industrial structure and fluctuations in the business cycle: analysis and testing based on the perspective of the labor market [J]. Management World, 2018, 34 (03): 51-67. 
[8] Li Xiaojuan. The Impact of China 's Industrial Structure Changes on Economic Fluctuations_-Research Based on Spatial Econometric Models [J]. Technology Economics and Management Research, 2017 (03): 105-109.

[9] Gan Chunhui, Zheng Ruogu, Yu Dianfan. The impact of China 's industrial structure changes on economic growth and fluctuation [J]. Economic Research, 2011, 46 (05): 4-16 + 31 .
[10] Zhou Ye'an, Zhang Quan. Fiscal decentralization, economic growth and volatility [J]. Management World, 2008 (03): 6-15 + 186 .

[11] Feng Yunting, Ji Liqun. Technological Innovation and Fluctuation of Urban Economic Growth-An Empirical Study Based on Panel Data of 15 Vice-Provincial Cities in China [J]. Industrial Technology and Economy, 2020,39 (01): 41-49. 